\title{
VARIABILITY AND CO-RELATIONSHIP OF BODY TRAITS IN WEST AFRICAN DWARF GOATS IN A TROPICAL HUMID ENVIRONMENT
}

\author{
O. M. A. Jesuyon and S. O. Olawumi
}

\begin{abstract}
Summary
To understand variability and phenotypic association among body traits in West African Dwarf goats, morphological traits were examined based on location and sex. Two hundred and twenty-seven (227) goats in two Nigerian states were surveyed. Randomized complete block with Factorial treatment design, GLM, Pearson's phenotypic correlation procedures of $\mathrm{SAS}^{\circledR}$ was employed. Morphological and index traits examined were body weight (BWT), hearth girth (HGH), diagonal trunk length (DTL), height at the withers (HWT), height at the rump (HRP); and Trunk length index (TLI), over-building index (OBI), body depth index (BDI), body breath index (BBI), withers-girth index (WGI), body-length index (BLI) and Weight-height index (WHI). BWT, DTL, TLI, OBI, BLI and WHI were influenced $(\mathrm{P}<0.05)$ by location, while DTL, TLI, OBI, BDI, BBI and BLI were influenced $(\mathrm{P}<0.05)$ by interaction of Location and Sex. Does recorded higher $(\mathrm{P}<0.05)$ BWT, TLI and BLI $(27.75,183.62$ and 156.33), while Bucks had higher $(\mathrm{P}<0.05)$ DTL, HGH, HWT, HRP, OBI, BDI, BBI, WGI and WHI $(80.57,58.78,46.89$, $46.36,99.29,126.01,127.01,-26.02$ and 45.83). Ekiti goats recorded higher OBI, while Osun goats were higher on DTL, TLI, BLI and WHI $(\mathrm{P}<0.05)$. Highest correlation for females and males were between BWT/WHI $(r=0.952 / 0.967, \mathrm{P}<0.0001)$; for BWT/WHI were $(\mathrm{r}=0.969 / 0.972,0.0001)$; and between HRP/HWT ( $\mathrm{r}=0.953 / 0.929, \mathrm{P}<0.0001)$ on Ekiti and Osun goats respectively. Between Ekiti and Osun goats BWT/WHI $(\mathrm{r}=0.969 / 0.972, \mathrm{P}<0.0001)$ and HRP/HWT $(\mathrm{r}=0.953 / 0.929, \mathrm{P}<0.0001)$ were obtained. CVs were highest on WGI (-69.65/-45.16); BWT (31.89/43.79), and WHI (29.25/35.54) for Does and Bucks; while WGI (-56.72/57.42), BWT (53.51/46.78) and WHI (42.09/36.76) were higher for Ekiti and Osun goats. Significant $(\mathrm{P}<0.0001)$ phenotypic correlation were obtained between BWT, DTL, HWT, HGH individually, and many other traits $(\mathrm{r}=0.336-0.957)$.
\end{abstract}

Keywords: Phenotypic correlation, coefficient of variation, Does and Bucks, Humid tropics, Index traits.

\section{Introduction}

West African Dwarf (WAD) goat is a predominant small ruminant breed raised by resource-limited households in the humid west and central Africa. It is unique for its adaptation to hot and humid environment, high fertility and prolificacy under backyard systems where they are raised almost with zero investment (Oseni and Ajayi, 2014). Rearing of sheep and goats has lasting social change by improving income and standard of living of rearing communities Okpeku et al. (2011). Important morphometric traits for evaluating phenotypic characters in meat goats include body weight, height at withers, body length, height at rump, heart girth (Hilal et al., 2013), chest depth, chest width, pelvic width (Maksimović et al., 2015); head length, neck length, ear length, horn length, tail length and leg length (Rotimi et al., 2017) and distance between eyes, ear width, paunch girth (Mahmud, 2014. Heart girth and cannon bone length was least affected by posture of an animal (Mahmud, 2014). Studies on standardized variability of these body traits and indices (SD/CV), which serve as open window for selection in domestic WAD goats have attracted attention in recent times (Hillal, et al., 2013).

Jesuyon, Oluwatosin M. A., Animal Breeding and Genetics Unit, Department of Animal Production and Health Federal University, P. M. B. 373, Oye-Ekiti, Ekiti State, Nigeria, corresponding author; e-mail: dr.oluwatosinjesuyon14@gmail.com, Olawumi, S. O. Department of Animal Science, Ekiti State University, Ado-Ekiti, Nigeria, e-mail: olawumisimeon@yahoo.com; 
In a study on the relative contributions of genes, environment and other factors on laboratory animal phenotype, Gartner (1990) demonstrated that only $20-30 \%$ of most random non-genetic variability was due to environmental factors, with the remaining $70-80 \%$ of non-genetic variation due to a 'third component effective at or before fertilization'. NCSS (2018) submitted that correlation coefficient between any two traits is a parameter of the bivariate normal distribution, as traits' values are considered as two random variables that vary together. Ojedapo (2013) reported that correlation measures deviation from the population mean in one trait of an individual as a function of the deviation from the population mean of the other when both traits are measured in their respective phenotypic standard deviation unit. It expresses observed relationship between phenotypic performances of different traits. Phenotypic correlation of traits among individuals within a geographical environment or location could be a common cause of phenotypic resemblance among them. The objectives of study were to investigate variability of traits due to sex and location in the hot humid environment and to examine phenotypic co-relationship among WAD goats from two states in the hot humid environment.

\section{Materials and methods}

Survey was conducted on two hundred and twenty-seven free-ranging and scavenging $\mathrm{Ni}$ gerian dwarf goats, consisting of 124 males and 103 females, in Osogbo and Ilesa (Osun State); and in Ado, Ikole (Ekiti State); between May 2015 and June 2017. All locations were in the humid forest zone of Nigeria. Five morphometric and seven morpho-structural index traits were employed to study variability and phenotypic co-relationship among the surveyed animals. Body weight (BWT), heart girth (HGH), diagonal trunk length (DTL), height at withers (HWT), height at the rump (HRP) were recorded on each animal as described by Orheruata and Olutogun (1984), Salako (2006), Fajemilehin and Salako, (2008) and Bahashwan, (2014). Body weight was measured with a field, portable, digital, electronic scale (model: WH-A08, made in China, Patent No: 201030634194.3 ) of $50 \mathrm{~kg}$ capacity, hung on a tripod stand, while linear measurements were taken with a tape rule and thread. All measurements were taken in the morning before animals were fed. From above, morpho-structural index traits were derived as below in formulas 1-7:

Trunk length index $($ Shape $)($ TLI $)=($ DTL/HWT $) * 100$

Overbuilding Index $(\mathrm{OBI})=(\mathrm{HRP} / \mathrm{HWT}) * 100$

Body Depth Index $(\mathrm{BDI})=(\mathrm{HGH} / \mathrm{HWT}) * 100$

Body Breadth Index $(\mathrm{BBI})=(\mathrm{HGH} / \mathrm{HRP}) * 100$

Withers-Girth Index $(\mathrm{WGI})=(\mathrm{HWT}-\mathrm{HGH}) / \mathrm{HWT}^{*} 100$. This index could be used to examine variation in post-natal fore-quarter development in WAD goat

Body length Index (BLI): (DTL/HGH)*100: When index is $>90 \%$ animal is long

or longigline; $86-88 \%$ is medium or medigline, while less than $85 \%$ is short or

brevigline (Chacon et al., 2011; Khargharia et al., 2015)

Weight-Height Index $(\mathrm{WHI}, \mathrm{kg} / \mathrm{cm})=(\mathrm{BWT} / \mathrm{HWT}) * 100$

The study design was Randomized complete block with factorial treatment design (RCBD). Fixed factor was Sex while the Random factor was Location. The mixed statistical linear model adopted was of the form:

$$
\mathrm{Y}_{\mathrm{ijk}}=\mu+\mathrm{S}_{\mathrm{i}}+\mathrm{L}_{\mathrm{j}}+\mathrm{SL}_{\mathrm{ij}}+\varepsilon_{\mathrm{ijk}}
$$


Where $\mathrm{Y}_{\mathrm{ijk}}=$ Body weight and linear body responses in Sex $_{\mathrm{i}}$, location $_{\mathrm{j}}$ and animal $_{\mathrm{k}}$. $\mu=$ overall mean of the population

$\mathrm{S}_{\mathrm{i}}=$ the fixed effect of $\operatorname{sex}_{i}$ of an animal (male and female; where $\mathrm{i}=1,2$ )

$\mathrm{L}_{\mathrm{j}}=$ the random effect of location ${ }_{j}$ of an animal (Ekiti and Osun, where $\mathrm{i}=1,2$ )

$\mathrm{SL}_{\mathrm{ij}}=$ interactive effect of Sex ${ }_{i}$ and location ${ }_{j}$.

$\varepsilon_{\mathrm{ijk}}=$ random error associated with record in sex i, location $\mathrm{j}$ and animal $\mathrm{k}, \mathrm{NID},\left(0, \delta^{2}\right)$.

Data collected were analyzed using the GLM, LSMEANS, Tukey HSD test and Pearson's correlation procedures to evaluate sources of variation affecting characters, least square means, correlation by SAS, 9.2 (2010). Hypothesis was that, correlation between sexes, and between states shall be similar.

$\mathrm{H}_{01}$ : Correlation ${ }_{\text {Does }}=$ Correlation $_{\text {Bucks }}$

$\mathrm{H}_{02}$ : Correlation ${ }_{\text {Ekiti }}=$ Correlation $_{\text {Osun }}$

\section{Results}

Table 1 reveals the mean square values for morphometric and structural index traits of the combined population of WAD goats under study. All traits studied were influenced $(\mathrm{P}<0.05)$ by sex; BWT, DTL, TLI, OBI, BLI and WHI were influenced by location $(\mathrm{P}<0.05)$; while DTL, TLI, OBI, BDI, BBI and BLI were influenced $(\mathrm{P}<0.05)$ by interaction of location and sex. RMSE for TLI (23.08) and BLI (20.03) were higher than RMSE values of other traits (4.8315.14). Results revealed high coefficient of variation for BWT, WGI and WHI); medium CV for DTL, HGH, TLI, HRP, BDI and BBI; and low CV for OBI (4.91). All models were significant $(\mathrm{P}<0.05)$ with low $\mathrm{R}^{2}$ from 0.074 to 0.306 .

Table 1: ANOVA mean square values for morphometric and structural index traits on West African Dwarf (WAD) goats of Ekiti and Osun States in South-west Nigeria

\begin{tabular}{lccccccccccccccc}
\hline \multicolumn{1}{c}{ SV } & df & BWT & DTL & HGH & HWT & HRP & TLI & OBI & BDI & BBI & WGI & BLI & WHI \\
\hline Model & 3 & $<0.001$ & 0.0001 & 0.0001 & 0.0001 & 0.0001 & $<0.0001$ & 0.0007 & $<0.0001$ & 0.0003 & $<0.0001$ & $<0.0001$ & $<0.0001$ \\
\hline Location & 1 & $316.72^{\mathrm{a}}$ & $5279.34^{\mathrm{a}}$ & 60.93 & 26.81 & 2.02 & $22673.57^{\mathrm{a}}$ & $99.34^{\mathrm{d}}$ & 11.08 & 70.25 & 31.88 & $13599.31^{\mathrm{a}}$ & $1412.45^{\mathrm{b}}$ \\
\hline Sex & 1 & $5307.70^{\mathrm{a}}$ & $1534.57^{\mathrm{c}}$ & $5951.37^{\mathrm{a}}$ & $1459.39^{\mathrm{a}}$ & $1782.98^{\mathrm{a}}$ & $5520.81^{\mathrm{b}}$ & $151.23^{\mathrm{c}}$ & $3775.62^{\mathrm{a}}$ & $3201.29^{\mathrm{a}}$ & $3775.62^{\mathrm{b}}$ & $17475.10^{\mathrm{b}}$ & $14299.51^{\mathrm{a}}$ \\
\hline LocxSex & 1 & 38.79 & $1051.68^{\mathrm{d}}$ & 52.70 & 9.79 & 36.45 & $7685.89^{\mathrm{a}}$ & $93.34^{\mathrm{d}}$ & $344.48^{\mathrm{a}}$ & $981.21^{\mathrm{a}}$ & 91.87 & $2725.17^{\mathrm{b}}$ & 259.07 \\
\hline Error & 223 & 58.30 & 229.28 & 66.97 & 37.92 & 29.41 & 532.79 & 23.33 & 207.28 & 198.10 & 147.09 & 401.11 & 174.60 \\
\hline RMSE & 7.64 & 15.14 & 8.18 & 6.16 & 5.42 & 23.08 & 4.83 & 14.40 & 14.07 & 12.13 & 20.03 & 13.21 \\
\hline Mean & 17.95 & 78.76 & 54.16 & 44.57 & 43.75 & 176.53 & 98.42 & 121.83 & 123.83 & -21.83 & 145.48 & 38.83 \\
\hline CV & 42.55 & 19.22 & 15.11 & 13.82 & 12.39 & 13.08 & 4.91 & 11.82 & 11.37 & -54.24 & 13.77 & 34.03 \\
\hline$R^{2}$ & 0.296 & 0.130 & 0.285 & 0.152 & 0.220 & 0.261 & 0.074 & 0.100 & 0.081 & 0.102 & 0.306 & 0.280 \\
\hline
\end{tabular}

Notes: BWT=Body weight, DTL=Diagonal trunk length, $\mathrm{HGH}=$ Heart girth, HWT=Height at the withers, $\mathrm{HRP}=$ Height at the rump, TLI $=$ Trunk length index, $\mathrm{OBI}=$ Overbuilding index, $\mathrm{BDI}=$ Body depth index, $\mathrm{BBI}=$ Body breadth index, WGI=Withers Girth index, $\mathrm{BLI}=$ Body length index, $\mathrm{WHI}=$ Weight height index, Significant levels: $\mathrm{a}<0.0001 ; \mathrm{b}<0.001 ; \mathrm{c}<0.01 ; \mathrm{d}<0.05$. Means with superscripts are significant within model. 
Table 2 compares the mean, standard deviation (SD) and CV of traits between sexes (does and bucks) of WAD goats. Does recorded higher mean BWT, TLI and BLI, while bucks had higher DTL, HGH, HWT, HRP, OBI, BDI, BBI, WGI and WHI. No significant $(\mathrm{P}>0.05)$ differences were observed between does and bucks for all traits. SD was low on HRP and OBI for does and bucks; but high on BLI and TLI for does and bucks, respectively. Other traits investigated recorded SD values of 4.07 - 45.83. WHI recorded highest SD of 45.83 among bucks. CV was low on OBI (4.79 and 5.13), high on WHI (29.25 and 35.54), BWT (31.89 and 43.79) and WGI (-69.65 and 45.16) for does and bucks respectively. CV on DTL and BLI were twice as high in males as females.

Table 2: Mean, Standard deviation and coefficient of variation for morphometric characters of WAD does and bucks of Ekiti and Osun States in South-west Nigeria

\begin{tabular}{lccccccccccccc}
\hline Location & $\mathrm{N}$ & $\begin{array}{c}\text { BWT } \\
(\mathrm{kg})\end{array}$ & $\begin{array}{c}\text { DTL } \\
(\mathrm{cm})\end{array}$ & $\begin{array}{c}\text { HGH } \\
(\mathrm{cm})\end{array}$ & $\begin{array}{c}\text { HWT } \\
(\mathrm{cm})\end{array}$ & $\begin{array}{c}\text { HRP } \\
(\mathrm{cm})\end{array}$ & $\begin{array}{c}\text { TLI } \\
(\%)\end{array}$ & $\begin{array}{c}\text { OBI } \\
(\%)\end{array}$ & $\begin{array}{c}\text { BDI } \\
(\%)\end{array}$ & $\begin{array}{c}\text { BBI } \\
(\%)\end{array}$ & $\begin{array}{c}\text { WGI } \\
(\%)\end{array}$ & $\begin{array}{c}\text { BLI } \\
(\%)\end{array}$ & $\begin{array}{c}\text { WHI } \\
(\%)\end{array}$ \\
\hline $\begin{array}{l}\text { Does } \\
\text { Mean }\end{array}$ & 103 & $27.75^{\mathrm{a}}$ & $76.59^{\mathrm{b}}$ & $49.04^{\mathrm{b}}$ & $41.77^{\mathrm{b}}$ & $40.61^{\mathrm{b}}$ & $183.62^{\mathrm{a}}$ & $97.38^{\mathrm{b}}$ & $117.96^{\mathrm{b}}$ & $121.18^{\mathrm{b}}$ & $-17.96^{\mathrm{b}}$ & $156.33^{\mathrm{a}}$ & $30.40^{\mathrm{b}}$ \\
\hline $\begin{array}{l}\text { Bucks } \\
\text { Mean }\end{array}$ & 124 & $22.26^{\mathrm{b}}$ & $80.57^{\mathrm{a}}$ & $58.78^{\mathrm{a}}$ & $46.89^{\mathrm{c}}$ & $46.36^{\mathrm{a}}$ & $170.65^{\mathrm{b}}$ & $99.29^{\mathrm{a}}$ & $126.01^{\mathrm{a}}$ & $127.02^{\mathrm{a}}$ & $-26.02^{\mathrm{a}}$ & $136.48^{\mathrm{b}}$ & $45.83^{\mathrm{a}}$ \\
\hline \multicolumn{1}{l}{} & & & & & & & & & & & & & \\
\hline Does SD & 103 & 4.07 & 9.97 & 5.30 & 4.21 & 3.85 & 20.50 & 4.66 & 12.51 & 12.27 & 12.51 & 15.58 & 8.89 \\
\hline Bucks SD & 124 & 9.75 & 19.69 & 8.94 & 7.37 & 6.43 & 29.69 & 5.10 & 11.75 & 11.24 & 11.75 & 25.82 & 45.83 \\
\hline & & & & & & & & & & & & & \\
\hline Does CV & 103 & 31.89 & 13.02 & 10.80 & 10.07 & 9.48 & 11.16 & 4.79 & 10.60 & 10.12 & -69.65 & 9.96 & 29.25 \\
\hline Bucks CV & 124 & 43.79 & 24.44 & 15.21 & 15.72 & 13.87 & 17.40 & 5.13 & 9.32 & 8.85 & -45.16 & 18.92 & 35.54 \\
\hline
\end{tabular}

Notes: BWT=Body weight, DTL=Diagonal trunk length, $\mathrm{HGH}=$ Heart girth, $\mathrm{HWT}=$ Height at the withers, $\mathrm{HRP}=$ Height at the rump, TLI $=$ Trunk length index, $\mathrm{OBI}=$ Overbuilding index, $\mathrm{BDI}=$ Body depth index, $\mathrm{BBI}=$ Body breadth index, WGI=Withers Girth index, BLI=Body length index, WHI=Weight height index. Means with superscripts are significantly different at $\mathrm{P}<0.05$.

Table 3 compares means, SD and CV between Ekiti and Osun goats. Ekiti goats had higher HRP (43.91 and 43.56) and OBI (99.12 and 97.54) while Osun goats recorded higher BWT, DTL, HGH, HWT, TLI, BDI, BBI, WGI, BLI and WHI (P>0.05). SD were least on TLI, HRP, HGH, HWT and BWT for Ekiti and Osun goats; but lower $(<13)$ for Ekiti on HWT, OBI, BDI and BBI and Osun goats on BWT, DTL, HGH, HWT, HRP, TLI, BLI, WHI. CV values were high on BWT, WGI and WHI (57.42-36.76); medium on HGH, HWT, HRP and BDI (17.5410.33 ) and least on OBI and BBI (4.39-9.70) for Ekiti and Osun goats. CV was higher among Ekiti than Osun goats on DTL, TLI, BLI by about 200\%. 
Table 3: Mean, Standard deviation and coefficient of variation for morphometric characters on WAD goats of Ekiti and Osun States in South-west Nigeria

\begin{tabular}{|c|c|c|c|c|c|c|c|c|c|c|c|c|c|}
\hline Location & $\mathrm{N}$ & $\begin{array}{c}\text { BWT } \\
(\mathrm{kg})\end{array}$ & $\begin{array}{l}\text { DTL } \\
(\mathrm{cm})\end{array}$ & $\begin{array}{c}\mathrm{HGH} \\
(\mathrm{cm})\end{array}$ & $\begin{array}{l}\text { HWT } \\
(\mathrm{cm})\end{array}$ & $\begin{array}{l}\text { HRP } \\
(\mathrm{cm})\end{array}$ & $\begin{array}{l}\text { TLI } \\
(\%)\end{array}$ & $\begin{array}{l}\text { OBI } \\
(\%)\end{array}$ & $\begin{array}{l}\text { BDI } \\
(\%)\end{array}$ & $\begin{array}{l}\text { BBI } \\
(\%)\end{array}$ & $\begin{array}{l}\text { WGI } \\
(\%)\end{array}$ & $\begin{array}{l}\text { BLI } \\
(\%)\end{array}$ & $\begin{array}{l}\text { WHI } \\
(\%)\end{array}$ \\
\hline Ekiti Mean & 127 & 17.22 & $74.49^{b}$ & 54.04 & 44.46 & 43.91 & $166.82^{\mathrm{b}}$ & $99.12^{\mathrm{a}}$ & 122.28 & 123.45 & -22.82 & $137.67^{\mathbf{b}}$ & $37.11^{\mathrm{b}}$ \\
\hline Osun Mean & 100 & 18.87 & $84.19^{\mathrm{a}}$ & 54.77 & 44.70 & 43.56 & $188.87^{\mathrm{a}}$ & $97.54^{\mathrm{b}}$ & 122.46 & 125.54 & -22.46 & $155.41^{\mathrm{a}}$ & $41.02^{\mathrm{a}}$ \\
\hline Ekiti SD & 127 & 9.21 & 18.34 & 8.39 & 7.27 & 6.50 & 30.31 & 5.39 & 12.64 & 11.91 & 12.64 & 26.76 & 15.62 \\
\hline Osun SD & 100 & 8.77 & 10.58 & 9.61 & 5.78 & 5.62 & 13.42 & 4.29 & 12.90 & 12.18 & 12.90 & 14.60 & 15.08 \\
\hline Ekiti CV & 127 & 53.51 & 24.62 & 15.52 & 16.36 & 14.81 & 18.17 & 5.43 & 10.33 & 9.65 & -56.72 & 19.44 & 42.09 \\
\hline Osun CV & 100 & 46.78 & 12.57 & 17.54 & 12.92 & 12.90 & 7.11 & 4.39 & 10.53 & 9.70 & -57.42 & 9.40 & 36.76 \\
\hline
\end{tabular}

Notes: BWT=Body weight, DTL=Diagonal trunk length, $\mathrm{HGH}=$ Heart girth, HWT=Height at the withers, $\mathrm{HRP}=$ Height at the rump, TLI=Trunk length index, $\mathrm{OBI}=$ Overbuilding index, $\mathrm{BDI}=$ Body depth index, $\mathrm{BBI}=$ Body breadth index, WGI=Withers Girth index, BLI=Body length index, WHI=Weight height index. Means with different superscripts are significantly different at $\mathrm{P}<0.05$.

Table 4 reveals pair-wise correlation between traits within does and bucks studied. Fewer phenotypic paired-trait correlations (47) were obtained within does than bucks (54). Within does, WHI correlated highly with BWT and BLI, WGI with BBI; BBI with BDI, HRP with HWT, HGH with DTL and BWT; DTL with HGH and TLI, and BWT with HGH and WHI (r $=0.708-0.952, \mathrm{P}=0.0001-0.01)$. Among bucks, WHI was highly correlated with BWT, DTL and HGH; BLI with TLI and DTL; WGI with BBI; BBI with BDI; OBI with DTL; TLI with DTL; HRP with HWT, HGH and BWT; HGH with BWT, HWT and DTL; HWT with BWT and DTL; DTL with BWT, HWT, TLI, BLI, WHI and HGH, and BWT with WHI, HGH, DTL, HWT and HRP $(r=0.719-0.967, \mathrm{P}=0.0001)$.

Table 4: Correlation matrix between morphometric and structural index traits on WAD does and bucks in Ekiti and Osun States in South-west Nigeria.

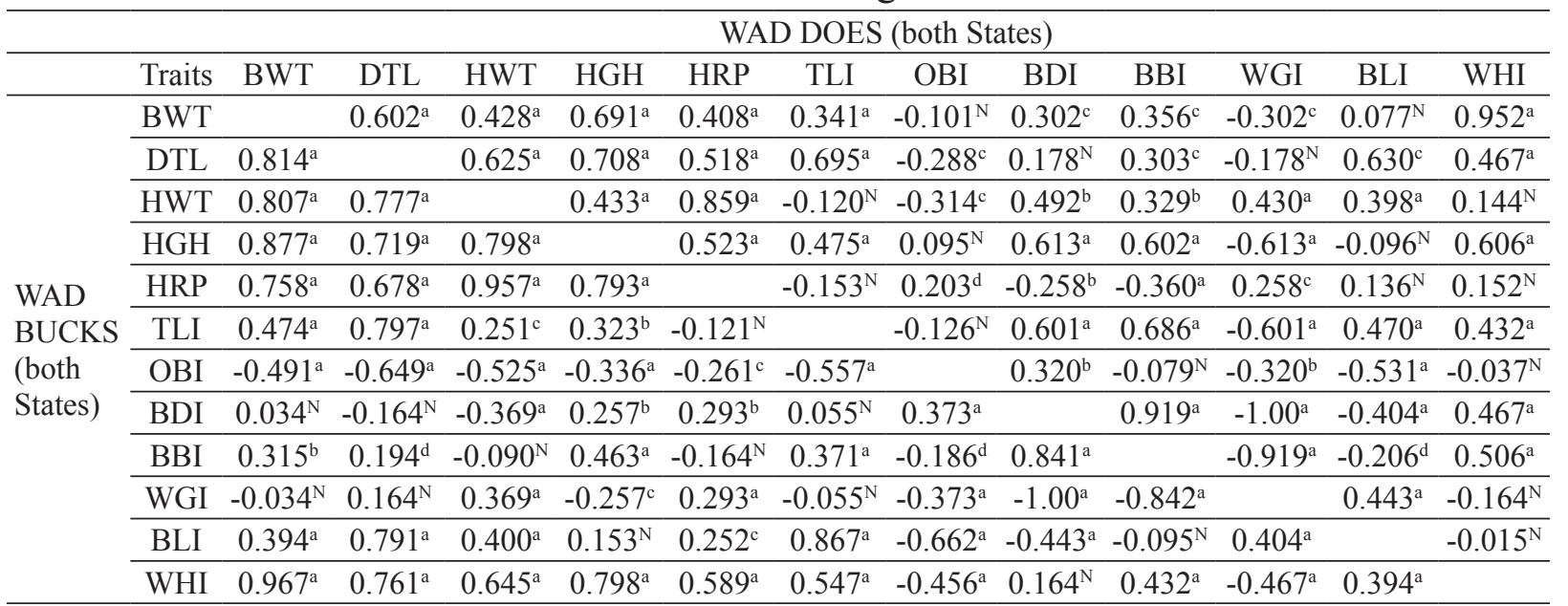

NOTES: BWT=Body weight, DTL=Diagonal trunk length, $\mathrm{HGH}=$ Heart girth, HWT=Height at the withers, $\mathrm{HRP}=$ Height at the rump, TLI=Trunk length index, $\mathrm{OBI}=$ Overbuilding index, $\mathrm{BDI}=$ Body depth index, $\mathrm{BBI}=$ Body breadth index, WGI=Withers Girth index, BLI=Body length index, WHI=Weight height index, Levels of significance: $\mathrm{a}=0.0001 ; \mathrm{b}=0.001 ; \mathrm{c}=0.01 ; \mathrm{d}=0.05 ; \mathrm{N}=$ Not significant. 
Table 5 shows the pair-wise correlation matrix for traits on WAD goats from Ekiti and Osun States. Ekiti showed that WHI was correlated with BWT and HGH; BLI with TLI, WGI, DTL and OBI; WGI with BBI; BBI with BDI; TLI with DTL; HRP with HWT, HGH and BWT; HGH with BWT and HWT; HWT with BWT and DTL; and DTL with BLI, TLI, HWT, while BWT correlated with WHI, HGH, HWT, HRP and DTL ( $\mathrm{r}=0.720-0.969, \mathrm{P}=0.0001)$. Among Osun goats, WHI was most correlated with BWT and HGH; BLI with BDI and BBI; WGI with BBI; BBI with BDI; HRP with HWT, DTL, HGH and BWT; HGH with BWT, DTL and HWT; HWT with DTL and BWT; DTL with HWT, HRP, HGH and BWT; BWT with WHI, HGH, HRP, DTL and HWT $(r=0.709-0.972, \mathrm{P}<0.0001)$ respectively.

Table 5: Correlation matrix between morphometric and structural index traits on WAD goats of Ekiti and Osun States in South-west Nigeria.

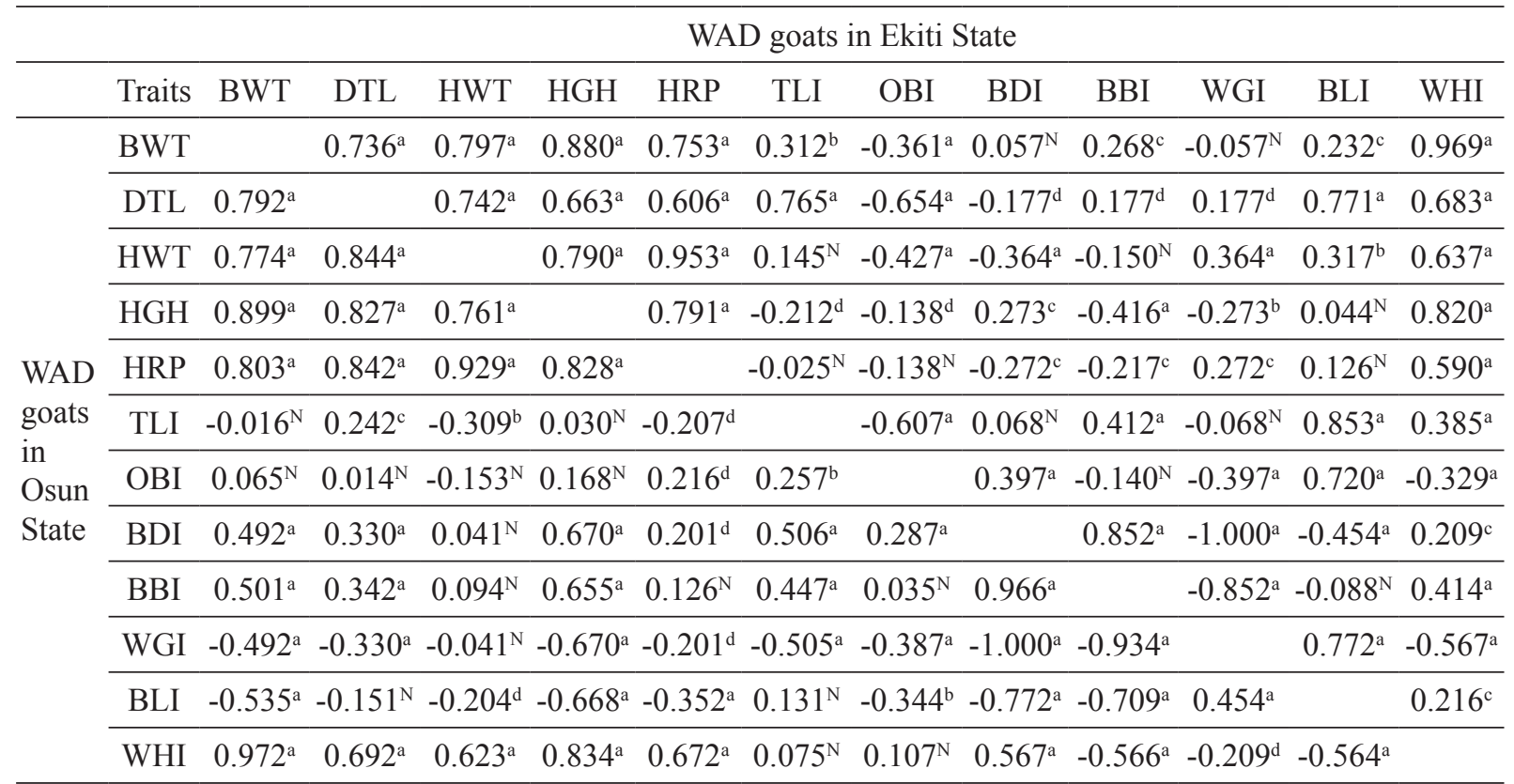

NOTES: BWT=Body weight, DTL=Diagonal trunk length, $\mathrm{HGH}=$ Heart girth, HWT=Height at the withers, $\mathrm{HRP}=$ Height at the rump, TLI=Trunk length index, OBI=Overbuilding index, $\mathrm{BDI}=$ Body depth index, $\mathrm{BBI}=$ Body breadth index, WGI=Withers Girth index, $\mathrm{BLI}=$ Body length index, WHI=Weight height index, Levels of significance: $a=0.0001 ; b=0.001 ; c=0.01 ; d=0.05, N=$ Not significant

\section{Discussion}

Findings revealed important variability within traits between sexes $(\mathrm{S})$, and within traits between locations (L). The interactions of LxS implied that DTL, TLI, OBI, BDI, BBI and BLI were highly influenced by sex and state. The high RMSE value for TLI and BLI revealed less accurate estimates by the model (RMSE, 2018) due to field data. The low $\mathrm{R}^{2}$ accounted for little variability for estimation from data. The higher mean values of BWT, TLI and BLI for does revealed indicator traits for sexual dimorphism between sexes during development, while the low SD values revealed stable traits: OBI, HRP, HWT, HGH, BWT- for characterizing and differentiating between WAD and some other breeds, sexes within breed and between state locations, as traits exhibited lowest variability between States. Between sexes, DTL and 
BLI produced greatest diversity on phenotypic level. SD values obtained from present study were highly heterogeneous, and above values of 7.49 to 0.96 obtained by Yakubu et al. (2010) on morphometric traits in WAD goat. CV indicates variability in relation to the sample mean size (Wiki, 2018). The CV values ( $>20)$ within BWT, WGI and WHI indicated traits exhibiting high level of variability. Thus WGI, BWT and WHI could serve as candidate traits in selection criteria for improvement of body weight-withers in goats in humid environment. Gomes (1985) classified CV as low $(<10 \%)$, medium $(10-20 \%)$, high $(20-30 \%)$ and very high $(>30 \%)$. This classifies all CVs on WGI, BWT and WHI as 'very high' and highly heterogeneous in the humid tropics, and was higher than $10.9-34.7 \%$ reported for eight qualitative morphological characters by Dekhili et al. (2013) on Algerian Setif goats.

Within sexes, there were more highly correlated paired-traits among bucks than does. Within sexes, DTL and BWT correlated with three to five other traits. Between sexes, bucks demonstrated higher magnitude of phenotypic correlation than does. OBI values were higher among bucks than does, thus differentiating between does and bucks, and correlating with DTL $(-0.654)$ and TLI $(-0.607)$ in males/bucks $(\mathrm{P}<0.05)$ but not significantly $(\mathrm{P}>0.05)$ correlated with other traits among females/does. Selection for DTL and BWT simultaneously within sexes could result in improvement of HGH, TLI, HGH and WHI (does); BWT, HWT, TLI, BLI, WHI, HGH, DTL, and HRP (bucks). Between sexes, significantly correlated traits vary greatly, and revealed many strong and positive phenotypic associations.

Within states, goats recorded significant correlations between paired traits; as Ekiti recorded twelve while Osun had twenty correlated pairs $(r \geq 0.700)$ for similar traits. Ekiti revealed higher values on HWT, OBI and WGI related-traits while Osun gave high values $(\mathrm{P}<0.05-0.0001)$ on BWT, DTL, HGH, TLI, BDI and BBI related-traits which could typify them between states respectively. Thus, both populations demonstrated phenotypic similarity on these traits, and confirm report by Roff and Mousseau (2005) that phenotypic traits correlation among populations of the same species vary among geographic locations, revealing the influence of environment on phenotypic relationship among ruminants. Between Ekiti and Osun states, the goat populations differed on OBI. While Ekiti goats demonstrated significant $(\mathrm{P}<0.0001)$ correlations between OBI and, DTL (0.654), TLI (-0.607) and BLI (0.720), while low correlation ( $\mathrm{P}>0.05)$ were obtained between OBI and other traits on Osun goats. HWT, OBI and WGI were highly correlated (0.969-0.567) with most of other traits among Ekiti goats while BWT, DTL, HGH, BDI and BBI were correlated (0.972-0.501) with many traits among Osun WAD goats. The respective paired-traits revealed similarity in phenotypic relationship between traits within environment. Other body parameters directly related to size displayed moderate to very highly positive correlation with other traits, making them potential selection criteria. OBI and WGI (on does and Ekiti goats) were negatively correlated with most other traits.

Correlation values and magnitudes vary greatly between environments, states, or geographical areas due to external environmental factors such as relief features, topography, climatic differences, and prevailing agricultural feedstuffs. Javed (2004) submitted that genetic correlations indicate that genes affecting one trait also affect the other traits. As number of replicates increase, phenotypic correlation approaches genetic correlation, and could be a fairly good estimator of genetic correlation in well-replicated experiments (IRRI, 2018). Most correlations between body measurements were positive and significant $(\mathrm{P}<0.05)$ for age groups of sheep 
studied, heart girth was most related to live weight $(r=0.98,0.72$ and 0.90$)$ in kids, growers and adults studied by Oke and Ogbonnaya (2011). Roff and Mousseau (2005) submitted that since selection is blind to genotype, it acts solely on phenotypic variation so that ability of species to evolve will be determined first by the phenotypic variation exposed to selection.

\section{Conclusion}

Study revealed strong phenotypic relationship on BBI and BDI related-traits for Does, and BWT, DTL, HWT, HGH, HRP and OBI related paired-traits for Bucks, respectively. Between environments, phenotypic correlation was high on BBI, HGH, BDI, BBI and BLI on Ekiti; while correlations on DTL, BWT, HRP and DTL were high on Osun WAD goats.

Declarations of interest: none.

Funding: This research did not receive any specific grant from funding agencies in the public, commercial, or not-for-profit sectors.

\section{REFERENCES}

1. ATGR (2018): Animal genetic training resource, World animal populations increase, but not everywhere, http://agtr.ilri.cgiar.org/index.php?

2. Bahashwan, S. (2014): Application of Morphometric Traits for Live Body Weight Estimation in Dhofari Calves, International Journal of Scientific Research in Agricultural Sciences, 1(5): 90-96.

http://dx.doi.org/10.12983/ijsras-2014-poogo-0096.

3. Chacón, E., Macedo, F., Velázquez, F., Paiva, S. R., Pineda, E., C. McManus (2011): Morphological measurements and body indices for Cuban Creole goats and their crossbreds, Revista Brasileira de Zootecnia,40 (8): Viçosa. http://dx.doi.org/10.1590/S151635982011000800007.

4. Dekhili M., M. Bounechada, I. Mannalah (2013): Multivariate analyses of morphological traits in Algerian goats, Sétif, north-eastern Algeria, Animal Genetic Resources, 52: 51-57. DOI: http://dx.doi.org/10.1017/ S2078633613000040.

4. EPI (2009): Earth Policy Institute, World Population of Cattle, Sheep, and Goats, 1967-2017. http://www.earthpolicy.org/datacenter/ xls/book_pb4_ch2_9-test.xls.

5. Fajemilehin, O. K. S., A. E. Salako (2008): Body measurement characteristics of the West African Dwarf (WAD) Goat in deciduous forest zone of Southwestern Nigeria, African Journal of Biotechnology, 7(14): 2521-2526.

6. Gartner, K. (1990): A third component causing random variability beside environment and genotype. A reason for the limited success of a 30 year-long effort to standardize laboratory animals? Laboratory Animals, 24: 71-77.

7. Hilal, B., S. El Otmani, , M. Chentouf, , I. Boujenane (2013): Morphologic characterizattion of the local goat population "Beni Arrous", Options Mediterraneennes, A. 108: 433-437.

8. Holstein association (2018): Linear type evaluations, http://www.holsteinusa.com/genetic_evaluations/ss_linear.html.

9. IRRI (2018): Correlation among Traits: implications for screening, http://www.knowledgebank .irri.org/ ricebreedingcourse/Lesson_8_Correlations_among_traits_implications_for_screening.htm. 
10. Javed, K., M. Abdullah, M. Akhtar, M. Afzal (2004): Phenotypic and genetic correlations between first lactation milk yield and some performance traits in Sahiwal cattle, Pakistan Veterinary Journal, 24 (1): 9-12.

11. Khargharia G., G. Kadirvel, S. Kumar, S. Doley, P. K. Bharti, M. Das (2015): Principal component analysis of morphological traits of Assam hill goats in Eastern Himalayan, Indian Journal Animal and Plant Sciences, 25 (5): 1251-1258.

12. Maksimović, N., F. Bauman, M. P. Petrović, V. C. Petrović, D. Ružić-Muslić, N. Mićić, I. MiloševićStanković, (2015): Productive characteristics and body measurements of Alpine goats raised under smallholder production systems in Central Serbia, Biotechnology in Animal Husbandry, 31 (2): 245-253. DOI: 10.2298/BAH1502245M.

13. Mahmud, M. A., P. Shab, U.Y. Zubairu, (2014): Live Body Weight Estimation in Small Ruminants A Review, Research, 2 (2): $102-108$.

14. Mwacharo, J. M.; A. M. Okeyo, G. K. Kamande, J. E. O. Rege (2006): The small East African shorthorn zebu cows in Kenya, In: Linear body measurements, Tropical Animal Health and Production, 38: 65-74.

15. NCSS 2018: Linear Regression and Correlation, Chapter 300, p. 2, https://ncsswpengine.netdna-ssl. com/wpcontent/themes/ncss/pdf/Procedures/NCSS/Linear_Regression_and_Correlation.pdf.

16. Okpeku, M., A. Yakubu, S.O. Peters, M.O. Ozoje, C.O.N. Ikeobi, O.A. Adebambo, I.G. Imumorin, (2011): Application of multivariate principal component analysis to morphological characterization of indigenous goats in Southern Nigeria, Acta Agriculturae Slovenica, 98: 101-109.

17. Ojedapo, L. O. (2013): Phenotypic correlation between the external and internal egg quality traits of Pharaoh quail reared in derived savanna zone of Nigeria, Journal of Biology, Agriculture and Healthcare, 3(10): 80-?.

18. Oke, U. K., Ogbonnaya, E. O. (2011): Application of Physical Body Traits in the Assessment of Breed and Performance of WAD Sheep in a Humid Tropical Environment, Livestock Research for Rural Development, 23 (2), http://www.Irrd.org/Irrd23/2/cont2302.htm

19. Orheruata M. A., O. Olutogun (1994): Pre and Post weaning relationship (phenotypic) between some N'dama cattle linear measurements in the tropics, Nigerian Journal of Animal Production, 22: 76-82. https://www.ajol.info/index.php/ ajb/article/viewFile/59069/47377.

20. Oseni, S. O., B. A. Ajayi, (2014): Phenotypic Characterization and Strategies for Genetic Improvement of WAD Goats under Backyard Systems, Open Journal of Animal Sciences, 4 (05): 253-262. DOI:10.4236/ ojas.2014.45032.

21. Philipsson, J., Zonabend, E., Bett, R. C., A.M. Okeyo, (2011): Global perspectives on animal genetic resources for sustainable agriculture and food production in the tropics, Animal Genetics Training Resource, Version 3, Ojango, J.M., Malmfors, B. and Okeyo, A.M. (Eds). International Livestock Research Institute, Nairobi, Kenya, and Swedish University of Agricultural Sciences, Uppsala, Sweden. http://agtr.ilri.cgiar.org/Documents/Modules/Global\%2operspectives.pdf.

22. RMSE (2018): Root-mean-square deviation, https://en.wikipedia.org/wiki/Root-mean-square_deviation.

23. Roff, D. A., T. Mousseau, (2005): The evolution of the phenotypic covariance matrix: evidence for selection and drift in Melanoplus, Journal of Evolutionary Biology, 18: 1104-1114.

24. Rodica, C., C. Ion, N. G. Carmen, (2014): Worldwide trends and orientations of raising goats. MPRA Paper No. 53460. https://mpra.ub.uni-muenchen.de/53460/1/MPRA_paper_53460.pdf.

25. Rotimi, E. A., Egahi, J. O., A. A. Adeoye, (2017): Body Characteristics of West African Dwarf (WAD) Goats in Bassa Local Government Area of Kogi State, World Scientific News, 69: 179-189. 
26. Salako, A. E. (2006): Application of morphological indices in the assessment of type and function in sheep, International Journal of Morphology, 24: 13-18,

27. SAS (2010): SAS/STAT Statistical Analytical Systems Computer software, SAS Institute Incorporated, N.C., USA.

28. Skapetas, B., V. Bampidis, (2016): Goat production in the World: present situation and trends, Livestock Research for Rural Development, 28 (11). http://www.lrrd.org/Irrd28/11/skap28200 .html.

29. Wikipedia (2018): Coefficient of variation, https://en.wikipedia.org/wiki/Coefficient_of_vari-ation.

30. Yakubu, A., A. E. Salako, I. G. Imumorin, , A. O. Ige, M. O. Akinyemi (2010): Discriminant analysis of morphometric differentiation in the West African Dwarf and Red Sokoto goats, South African Journal of Animal Science, $40(4): 381-387$. 